\title{
The impacts of digital infrastructure transformation on livestock system sustainability in rural communities
}

\author{
Gwaka L, May, J and Tucker, W
}

Investments in digital infrastructure in marginalised communities are set to increase in the next decade. These are premised on the potential of digital technologies to contribute towards solving societal problems, including the fragility of food value chains in rural areas. Although there are mixed empirical findings on the impact of these digital infrastructure investments, huge investments are continuing amid changing ICT policies in most developing countries. This paper, using a case study of a local livestock value chain in a rural community in Zimbabwe, argues for the application of non-conventional approaches towards digital infrastructure transformation impact assessment. Using selected theories and frameworks (socio-ecological systems framework, choice framework and technology affordances theory) as well as empirical data from a project in a rural community, the paper shows that real-time impact assessment using context-specific metrics may reveal hidden digital infrastructure transformation impacts, positive and negative, that are often overlooked when traditional impact assessment approaches are employed. The findings of this study contribute towards improving approaches towards ICT impact assessment. Practitioners engaging in impact assessment are challenged to move beyond dependence on traditional metrics (e.g. access) to the adoption of participatory processes to decipher contextappropriate metrics.

Keywords: social context, food value chains, impact assessment, Zimbabwe 


\section{Introduction}

Rural communities in sub-Saharan Africa are characterized by high levels of poverty and poor access to infrastructure, both physical and digital (IFAD, 2016). Even though there are contestations on the contributions of digital infrastructure ${ }^{1}$ towards the development of rural communities (Friederici, et al., 2017), the lack of digital infrastructure can act as a poverty trap. For instance, the lack of digital infrastructure in rural communities precludes the rural population from participating in the growing digital economy, exacerbates information asymmetries and perpetuates social exclusion. Studies such as that of Rey-Moreno et al. (2016) argue that due to limited competition, particularly mobile network connectivity, accessible digital services (voice calling/data services) are excessively expensive to the households in rural communities. Addressing digital infrastructure gaps in rural communities remains therefore an urgent matter as is reflected by national and regional efforts such as the African Union's Programme for Infrastructure Development in Africa (PIDA). Simultaneously, the private sector perceives technological innovations (such as digital platforms) as an opportunity to make profits while helping the marginalised (Kuriyan et al., 2012:1). This has encouraged the emergence of technological innovations aimed at marginalised communities in recent years.

The ubiquity of technological innovations in poor societies has prompted studies exploring multiple aspects relating to these technological innovations such as design, adoption, and use. Studies such as Ganju et al., 2015; Gigler, 2011; and Sabbagh \& Friedrich, 2012 are concerned with the potential impacts of these technological innovations on societal well-being, or broadly, development, of these marginalised communities (Avgerou, 2010). With the term 'development' itself being contested (ibid), studies have gone further to investigate the impacts of digital innovations on specific sectors such as education, health systems and agricultural systems (cf. Heeks, 2014; Majchrzak et al., 2016; Walsham, 2017). Despite the breadth of technological innovations, the integration of ICTs in rural communities has been biased towards these few sectors, resulting in a similar bias concerning studies of the impact of ICT in rural communities. With limited integration of technological innovations in specific local value chains, there are also limited studies which examine the impacts of technological innovations on local value chains such as a livestock system and natural resources in rural communities $^{2}$ (cf. Marshall, 2015; Foster et al., 2018).

Admittedly, rural communities have poor digital infrastructure which has resulted in limited integration of information and communication technologies (ICTs) in all forms of local value chains. Stringent regulations, policies, complex socio-economic and political dynamics have been noted to harbour the efforts to improve digital infrastructure in rural communities (Gwaka et al., 2018; Takavarasha and Makumbe, 2012). Studies are now emerging to explore ways and opportunities arising from digital infrastructure

\footnotetext{
${ }^{1}$ Sørensen (2013: np) refers digital infrastructure as "Equipment; the information itself; the applications and software; the network standards and transmission codes facilitating interconnection and interoperation; and the people who create the information, develop applications and services, construct the facilities etc."

${ }^{2}$ The lack of studies focusing on local food value chains is important for two main reasons; the local value chains such as livestock systems have been identified as critical towards achievement of global targets such as ending hunger (Sustainable Development Goal 2 - see, Committee on World Food Security, CFS, 2016)). Secondly, despite the importance of the local value chains, they are also increasingly fragile.
} 
transformation in complex contexts such as the countries in sub-Saharan Africa. Some conclude that, through changes in political and regulatory environments, there are opportunities to transform digital infrastructure in rural communities (Gwaka et al., 2018). Zimbabwe is an example of such a complex yet transforming context. For instance, the countenancing of the community networks by Zimbabwe's telecommunications regulatory agent, POTRAZ, shows that it is possible to establish low-cost networks and improve digital skills of local community members in rural communities. Taking advantage of these changes, various organisations are conceptualising and implementing ICT projects such as the Mobile Solutions for Marginalised Communities (MOSMAC). ${ }^{3}$ Such initiatives in rural communities may result in increased calls to integrate digital technologies in local value chains.

However, with the integration of digital technologies in local value chains imminent, the major challenge remains accurately determining the impacts of such digital technologies on the sustainability of such local value chains; and more broadly, the reduction of poverty, considering the criticism on current impact evaluation processes (cf. Pather \& Uys, 2010). To this end, there is need for developing and/or improving impact assessment processes. For instance, Pawson (2006:14) suggests undertaking intervention impact assessments which "[n]o longer aim at the simple issue of charting the success or failure of specific interventions" but ask "evaluation questions [which] rove over the topics of when, where, why, for whom and in what respects [interventions] work, as well as how, in what manner and at what cost." Also, applying a systems thinking approach to evaluation hold considerable attraction. Picciotto (2014:10) suggests that the systems thinking approach "adopt(s) networks as the privileged unit of account, explore interrelationships and engage with multiple actors, use concepts, symbols and diagrams to guide evaluative inquiry and probe the multiple loops that illuminate a changed preoccupation from 'attribution' to 'contribution" We argue that using this approach would enable the achievement of robust and comprehensive impact assessment which can yield relevant results for policy decisions (Mthoko \& Khene, 2018).

Given the foregoing, this paper focuses on investigating the blending of multiple approaches for impact assessment of the MOSMAC intervention on the sustainability of the livestock value chain in rural Zimbabwe. The paper uses empirical evidence generated from the project in Beitbridge community in Zimbabwe, and selected theories as the analytical frameworks, towards a critical investigation into the intervention's impacts. The selection of a single system, the livestock system, is based on a suggestion from Foster et al. (2018:73) that, even though some [interventions] are more compatible with other value chains, their "...impacts are likely to be shaped by the characteristics of the specific sectoral value chain." By undertaking a critical analysis of the impact of an intervention, the study contributes towards the process of identifying and selecting interventions which work, and which need to be scaled or promoted within rural communities. Furthermore, through extensive analysis of the livestock system, this nature of inquiry contributes to the existing efforts to establish "where the problems lie and what [needs] to be done" (Anadon et al., 2015:4) within local value chains.

\footnotetext{
${ }^{3}$ The MOSMAC project was implemented by the first author through a grant from USAID with the aim to improve the agricultural returns for the smallholder farmers, including livestock farmers, through digitisation of the value chain. The project implementation and subsequently the research inquiry, is developed from the presupposition that digital infrastructure transformation interventions in rural communities are driven by their potential to contribute towards overcoming societal challenges such as the fragility of the food systems
} 


\section{Critical perspectives on technology impact assessment}

In Africa, digital infrastructure investments (ICTs and other technologies, including revision of old and adoption of new regulatory frameworks) have increased over the years (Batuo, 2015; Friederici et al., 2017). Governments and other actors such as NGOs and international organisations are committing to change the digital infrastructure landscape in developing countries (Batuo, 2015). This has largely been based on the promises of being connected to affordable ICTs. However, despite huge investments in digital infrastructure, evidence on impact is unconvincing. In short, despite the uptake of ICTs, the livelihoods of many individuals and/or households in developing countries have not improved much (cf. Harris, 2016; Qureshi, 2015), while in other cases, ICT uptake has been linked to poverty reduction, albeit marginally (May et al., 2014). Justifiably, studies have ensued questioning the significance of transforming digital infrastructure in developing countries (Palvia et al., 2018). However, the methods of assessing digital infrastructure impact on societies applied across studies (and non-academic evaluations) have been questionable (Gomez \& Pather, 2012).

Since most rural areas lag in technology, technology transfer to these rural communities has mostly been based on top-down models. Thus, superior groups and not the intended users, dictate the process of technology transfer (Westerveld, 2012). With limited knowledge on digital technologies and an inferiority complex of the recipient communities (to question the technologies and those who bring the technologies), limited, if any, community-based technology assessment occurs. ${ }^{4}$ Limited assessment has also been conducted by project instigators, with little community participation (this is despite the adoption of human-centered design principles), exceptions being Oosterlaken (2009) and Atwood et al. (2013). Ely et al. (2014) show that in developing countries, technology assessment has been much less common than in developed countries. Contrastingly, in developed countries, technology assessment has existed for many years, and Schot and Rip (1997:251) posit that, this was prompted by the need to "reduce the human costs of trial and error ... of new technologies ... by anticipating potential impacts and feeding these insights back into decision making, and into actors' strategies". The late (or in some cases, the inexistence of) technology assessment in marginalised communities stimulates critical questions on whether there are concerns around human-related costs of trial and error of technologies in marginalised communities or not.

Apart from the limited technology assessment initiatives, there are also concerns with the impact assessment approaches. Ely et al. (2014:509) show concern that "technology assessment in developing countries tends to have been largely technical in nature, carried out within centralized institutions or by external consultants." Furthermore, technology assessment often fails to appraise advances in the wider social, environmental, and economic implications of digital infrastructure transformations (Ely et al., 2014:506). In supporting this, Gomez and Pather (2012:11) also show that attempts to conduct ICT evaluations in developing countries have focused much more "on measuring quantifiable, tangible outputs and outcomes of the ICTD interventions". Further to this, Guston and Sarewitz (2002) as well as Pather (2017) also suggest that the timing of technology impact assessment needs to be shifted to ensure that technology assessments are not only done at the end of the projects but are also done in real-time (e.g. at planning stage, during

\footnotetext{
${ }^{4}$ This study does not distinguish between technology assessment (e.g. product appropriateness) and technology impact assessment (outcomes based on the technology product). Therefore, technology assessment and technology impact assessment are interchangeably used.
} 
implementation and post implementation). It is argued that the practice of real-time technology assessment results in maximizing articulation of the potential benefits by the society, minimizing risks associated and promoting community responsiveness to the ICT project (cf. Guston \& Sarewitz, 2002:95). Finally, a critical element to consider in impact assessment is the focus of the evaluation. Successes of ICT intervention differ based on the intended goal of the project. For instance, Pather (2017:256) suggests that success of an information system can be defined by the system's achievement of the goal it is designed for. On the other hand, Toyama (2017) suggests that an information system's success can be judged by how it helps communities achieve their aspirations, hopes and dreams.

\section{Study problem: the gap in impact assessment}

Over the past decade, Zimbabwe has experienced a series of socio-economic challenges such as unemployment, poverty, economic crisis, and political turmoil. While these challenges are endured by Zimbabwe as a country, studies show that households in rural areas such as Ward 15 of Beitbridge District often face enormous risks (Kinsey et al., 1998). Like other rural districts, Beitbridge faces several challenges ranging from poor infrastructure and biodiversity losses to food insecurity. Among these challenges, recent studies including the ResilientAfrica Network study (Cooke, 2015) suggest that a lack of infrastructure is prominent among the key contributors of fragility in rural communities. In the context of this study and in relation to the livestock system, the lack of digital infrastructure becomes more visible with several studies (e.g. Gwaka, 2017; Prinsloo \& De Villiers, 2017) proposing that emerging technologies have the potential to play a role towards achieving and maintaining sustainable livestock systems. Furthermore, Foster et al. (2018) suggest that the adoption and use of emerging technologies such as mobile phones can help overcome some challenges within value chains. However, the potential of emerging technologies is often thwarted by the lack of digital infrastructure in rural communities. Yet studies such as Rey-Moreno et al. (2016); Gwaka et al. (2018); Van Stam \& Mweetwa (2012); and Westerveld (2012) show that it is possible to overcome digital infrastructure deficits in rural communities by adopting low cost bottom-up measures. Thus, governments and non-governmental organisations are committing resources to improve digital infrastructure in Africa. To this end, several ICT interventions are being rolled out in rural communities including the MOSMAC project in Beitbridge.

Interventions like the MOSMAC project are likely to increase in the coming years. These interventions will be premised on their perceived potential to contribute towards solving societal problems, including solving the fragility of critical value chains in rural areas, such as the livestock value chain. However, to date, there are mixed empirical findings on the impacts of such interventions on the overall development of poor societies. In the same vein, there are on-going debates relating to impact assessment, including how impact is defined in different contexts, the timing of intervention impact assessment and the metrics used to measure impact. The approaches that are available also excessively simplify the complex reality to a point that they are unable to account for the changes that have taken place (cf. Donner \& Toyama, 2009; Pather \& Uys, 2010). Thus, it is of concern that the process of impact evaluation remains unclear (Pather \& Uys, 2010). Evidently, existing impact evaluation metrics of digital interventions are marred with many problems. Also, most evaluations have focused on understanding the effects of technologies on societies rather than understanding how to actively shape the effects of 
technologies on societies to achieve society-desired outcomes or broadly, evidence translation (cf. Mackenzie \& Wajcman, 1999). It is within this context that this study aims to blend impact assessment approaches as part of efforts to improve the impact assessment process, particularly of ICT interventions.

\section{Study context and methods}

To address the gap alluded to in the previous sections, the study draws from three purposively selected theories (frameworks) to explore the potential impacts of digital infrastructure transformation on the livestock system in Beitbridge. The three selected theories are 1) socio-ecological system selected to explore the livestock system attributes, 2) choice framework to explore the development outcomes and 3) technology affordances to explore technology aspects. Using the tenets of these theories and frameworks, the study explores the potential impacts of digital infrastructure transformation on the livestock system. This study was conducted in Ward 15 in Beitbridge District which is located in Matabeleland South Province, in Zimbabwe (Vogt et al., 2015). The study area consists of 4 villages with an estimated population of 4166 people and 932 households (ZimStat, 2016:77). In Ward 15, poverty levels are higher than that of Zimbabwe as a whole. Empirical findings are generated from data collected in rural communities of this area between 2015 and 2018 during the implementation of the MOSMAC project. Since the MOSMAC project was implemented by the first author through a grant from USAID, this study emerges as part of self-reflection on development practice (Sherwood et al., 2019). ${ }^{5}$ Data were collected using qualitative ethnographic methods including focus group discussions $(n=9)$, continuous participant observation, key informant interviews $(n=8)$, official meetings and community workshops $(n=2)$. In all cases, sample sizes were purposively determined. During these sessions, various data sets were collected including photographs, field notes and audio-recordings. The data analysis process was iterative. Ethical clearance for data collection was obtained from the University of the Western Cape Human Subjects Research Ethics Committee (Reference number: HS17/3/2).

\section{Theoretical approaches to investigate impact}

This section presents impact assessment from a theoretical perspective. Thus, it seeks to demonstrate the anticipated impact of the MOSMAC intervention based on three selected theories. Ostrom's (2009) socio-ecological system (SES) approach is applied to examine the characteristics of the livestock value chain and subsequently the potential impacts of digital infrastructure transformation. The study also applies Kleine's $(2010 ; 2013)$ Choice Framework to assess the impacts of digital infrastructure on the livestock system. To determine how and when impact occurs, the study applies technology affordances theory (cf. Gaver, 1991; Leonardi, 2012). Following this, the study will present context-sensitive impact assessment based on lived-realities and voices of the community.

\footnotetext{
${ }^{5}$ Self-reflection is common in nursing practice and can be applied in ICT4D to provide practitioners an opportunity to reflect on their work e.g. "individuals can acknowledge and appreciate a job well done, reflect on and value the activities [done]. Reflective practices provide an evidence-informed framework to examine professional practice, promote self-awareness, enhance self-esteem, improve performance, and move toward professional maturity (Sherwood et al., 2019:32)
} 


\section{Socio-ecological systems framework}

The livestock system is complex (Marshall, 2015) and determining the impacts of an intervention on a livestock system is also inherently complex. Ostrom's (2009) SES framework serves as a diagnostic tool towards understanding complex systems, including livestock systems (McGinnis \& Ostrom, 2014; Marshall, 2015). The tenet of the SES framework is that a socio-ecological system comprises both primary and secondary attributes that interact to produce specific outcomes. Table 1 demonstrates that poor attributes of SES may contribute to a system fragility. The study therefore postulates that the transformation of digital infrastructure (technology attribute) through an intervention, can reshape the structure of the entire socio-ecological system and the interaction of SES attributes.

Table 1: Applying the SES framework (selected attributes) to analyse the Beitbridge livestock system

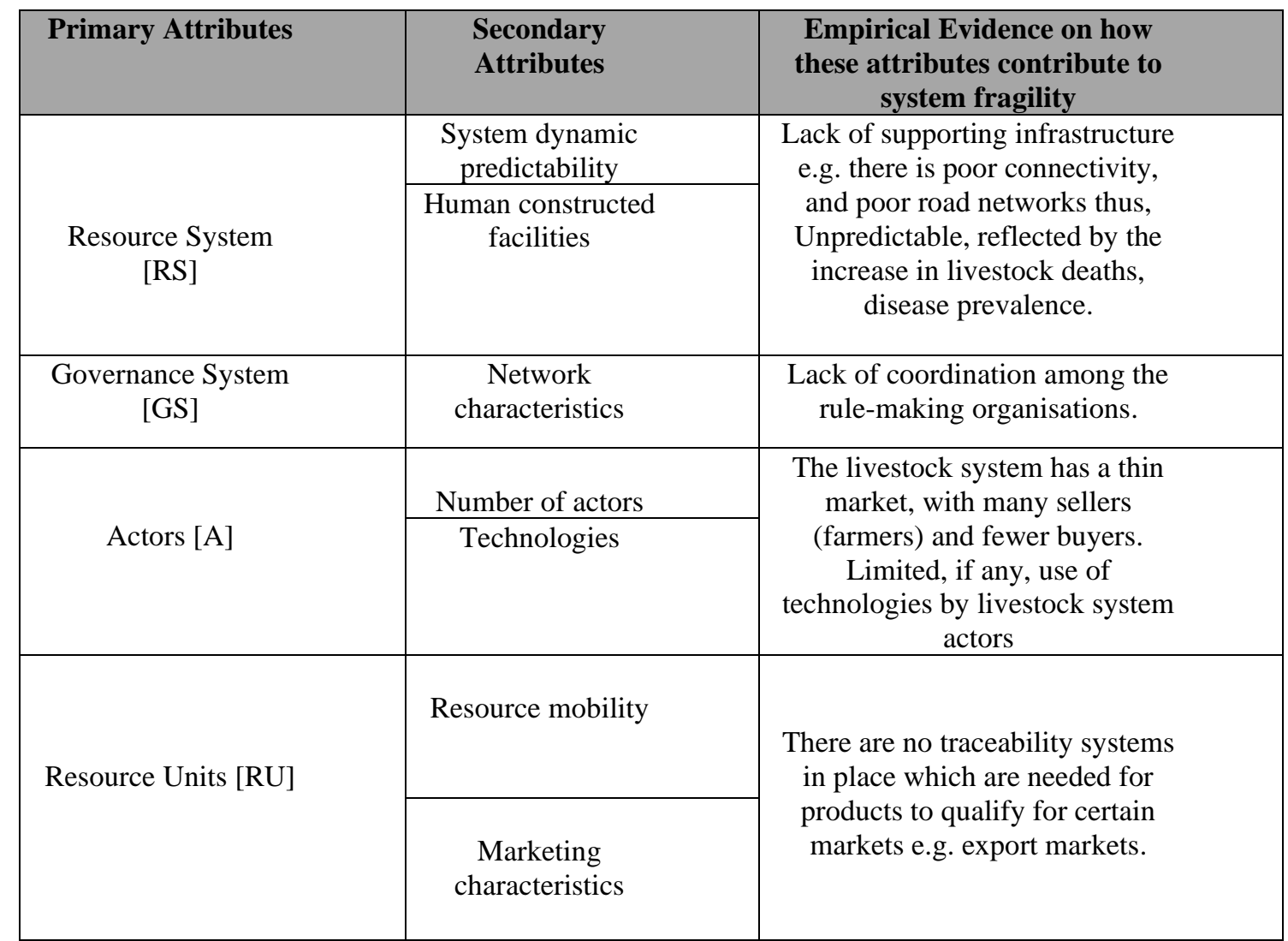

As Table 1 shows, the availability (or lack thereof) of human-constructed facilities and (un)predictability of the system dynamics determine the sustainability of a value chain. Studies such as that of Mavedzenge et al. (2008) specifically argue that infrastructure relating to livestock in rural communities is poor. Such a lack of appropriate infrastructure (including digital infrastructure) subsequently contributes to the difficulty of predicting seasons (also, partly due to climate change), unpredictable productivity, and limited access to information. From a governance system [GS] perspective, the attributes of an SES include network characteristics, rule-making organisations, and geographic scale of the system and policy area. The network characteristics relate to the "connections among the rule-making organizations and the population subject to these rules" (McGinnis \& 
Ostrom, 2014). Many studies argue that poor governance of local level systems and/or value chains contribute to the fragility of these systems and/or value chains. In addition to the [GS] attribute, a SES can also be examined from the actors attribute [A]. The actors' secondary attributes include the number of system actors, their socioeconomic characteristics, location, and technologies used. Existing studies on rural commodity markets suggest that the markets are usually thin, with limited buyers and more sellers (Gwaka, 2017). Furthermore, the system actors are usually poor, surviving on less than the poverty line. Also, since the actors are in rural areas (location), there is limited, if any, use of digital technologies within the livestock system. Finally, the last primary attribute in the SES of the livestock system is resource unit mobility [RU]. In the context of this study, livestock mobility is critical in monitoring livestock health and diseases through surveillance. Furthermore, consumers are increasingly requesting information on products they consume (traceability). Thus, it has become a requirement to monitor the mobility of livestock, which farmers in rural areas such as Beitbridge are unable to do; resulting in their products failing to qualify for lucrative national and international markets.

Having used the SES framework to describe the livestock system, it is also possible to apply the same framework to undertake impact assessment of an intervention directed towards the livestock SES. Firstly, digital infrastructure transformation directly represents a transformation of the [RS], specifically human constructed facilities. The existence of information centres and improved connectivity through digital infrastructure transformation efforts create supporting infrastructure for the local systems and/or value chains. In connection to this, the transformation of digital infrastructure also creates an opportunity for the integration of digital technologies into the livestock system which has further potential to impact system dynamics predictability. This presumption is supported by Enenkel et al. (2015) who suggest that using new technologies and innovative collaboration has the potential to improve decision-support and subsequently, the productivity of the resource systems. Further to this, there is evidence that technological innovations such as remote sensing, geographic information systems (GIS) and communication networks can play a major role in the seasonal forecasts which can improve the predictability of system dynamics (Ospina \& Heeks, 2010:6). In turn, these technology advances can also be critical in influencing the [RU], specifically resource mobility. In the context of livestock systems, Prinsloo and de Villiers (2017) argue that the transformation of digital infrastructure is critical for the implementation of livestock traceability systems. With digital transformation creating an opportunity to enhance traceability, the marketing characteristics of the resource units (livestock) can also be enhanced. In terms of governance system [GS], there is growing evidence on the use of digital technologies among individuals and organisations (including for social purposes) which can improve connections among the livestock system actors (network characteristics). Thus, digital infrastructure transformation can contribute towards improving connections among organisations and individuals within the livestock system. These improved connections are critical to the self-organisation of the actors [A] within the system (e.g. it can lead to collective marketing). In the same vein of improved connections, digital technologies create opportunities to increase the number of actors participating in the livestock system. Furthermore, there are propositions that the development of infrastructure can improve the economic development of communities. Thus, the transformation of digital infrastructure may lead to improved connections and improved social capital and may improve the socio-economic attributes of the farmers within the community. 


\section{The Choice Framework}

Another framework which can be used to undertake an intervention's impact evaluation is the Choice Framework (CF). In the CF, Kleine $(2010 ; 2013)$ suggests that the structure of a community and agency (of an individual or a group) combine to give dimensions of choice (e.g. existence of choice, use of choice) and ultimately influence the development outcomes (with choice as the primary outcome). The CF proposition is similar to the SES framework in that both frameworks suggest that within a system, there is an interaction of elements, e.g. the SES framework refers to the interaction of attributes, while the CF refers to interaction of structure and agency. A closer analysis shows that some of the elements under structure and agency in the CF are also classified as attributes in the SES framework. However, the major difference is that, in the CF, Kleine (2010; 2013) expands on the outcomes of these interactions, an aspect which the SES framework does not achieve. The CF shows that outcomes of interaction of agency and structure (attributes in SES) are dimensions of choice; and yet, in the SES framework, outcomes of the interaction of attributes are left to the imaginations of researchers and practitioners.

In the CF depicted in Figure 1, Kleine (2010) suggests that the structure includes the following elements: institutions and organisations, discourses, policies and programmes, formal and informal laws as well as access to ICTs. On the other hand, the agency comprises education resources, social resources, cultural resources, and health resources among others. In the context of the study, it is argued that there is limited use of ICTs (technologies) in local value chains such as the livestock system due to lack of access to ICTs as well as complex and restrictive regulations. Furthermore, most of the system actors in rural areas lack the prerequisite agency (e.g. skills to use ICTs, resources to access ICTs). It can be argued that using the CF, the fragility of the systems in rural communities can be linked to the poor structure and agency of rural communities. To this end, it can therefore be argued that the impacts of digital infrastructure transformation in the community can be determined based on how such an intervention impacts both the structure and agency of the community.

In terms of structure, digital infrastructure transformation can impact the ways in which existing institutions and organisations operate (function) or even prompt the emergence of new institutions and organisations such as the Remote Livestock Marketing System (RLMS), an online livestock business. From an operations perspective, the ubiquity of technology has the potential to contribute towards improved coordination among system actors such as the extension workers who can make use of social network technologies to communicate official information. Apart from the structure-related changes, the digital infrastructure transformation in a community can also impact the community's, an individual's and/or household's agency. For instance, the establishment of low-cost community networks and community information centres as well as training of individuals on ICTs in rural areas can result in improved information, social and education resources. Through the CF lens of analysis, the transformation of digital infrastructure in rural areas amounts to the transformation of the agency and structure of a community ultimately shaping the dimensions of choice for the community, individuals, and households. This transformation also translates to the alteration of the existence and sense of choice and the use of the choice. 


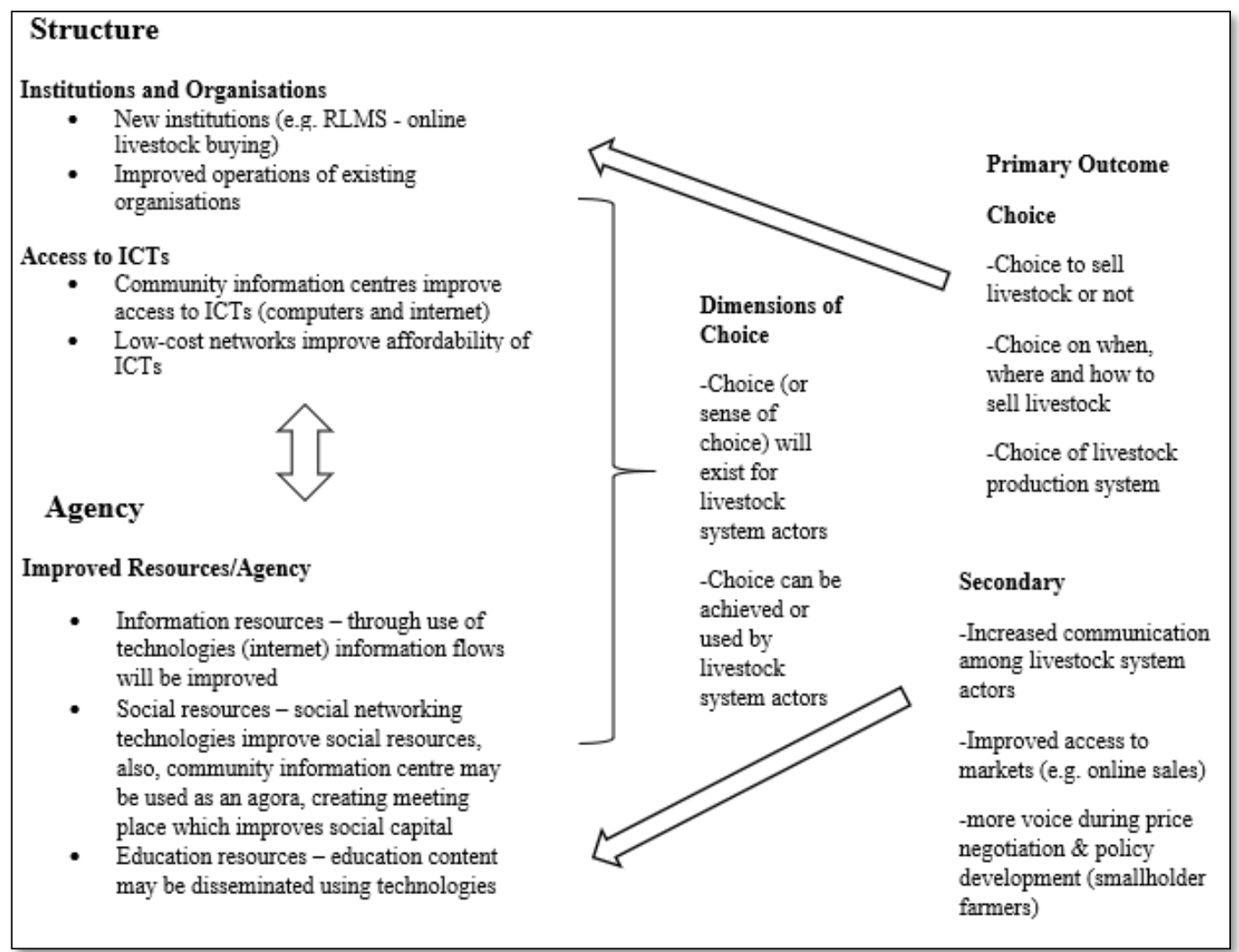

Figure 1: Using the CF to explore the impacts of digital infrastructure transformation on the livestock systems (adapted from Kleine 2010).

However, these potential theoretical impacts need to be critically evaluated. For instance, farmers may know of alternative markets offering competitive prices but due to lack of transport are not able to participate in these markets. Likewise, from the use of digital technologies, farmers may know of market prices (market information) but due to abject poverty and a weak negotiating position, they may be forced to accept sub-optimal prices. It is therefore critical to further establish how and when digital infrastructure transformation impacts the livestock systems; particularly knowing that it can be difficult to determine clear cause and effect of technology and development. For example, following Jensen's (2007) study on use of ICTs among fishers in Kerala, Srinivasan, and Burrell (2015) provided a critique of the role of ICTs in market price. In other words, context is often more critical than the introduction of ICT and can constrain the possible choices.

\section{Technology Affordances theory}

In addition to the SES framework and the $\mathrm{CF}$, the impacts of digital infrastructure transformation can be explored using technology affordance theory. Digital infrastructure transformations bring new technologies to communities and these technologies come with specific affordances. However, the communities in which these technologies are introduced need to possess certain skills and knowledge to be able to identify and utilise the technology affordances. Thus, skills development among community members is critical to promote the realization of technology affordances on existing and new technologies. This is highlighted in Gaver's (1991:80) argument that, "[w]hether a handle with particular dimensions will afford grasping depends on the grasper's height, hand size etc." Gaver's claim can be extended beyond individuals to include institutions and groups. 
In this regard, it is prudent to further suggest that the expected digital infrastructure transformation impacts on the livestock system in the study area depend on the appropriation of technology affordances by the system actors (individuals, institutions or groups) as well as other attributes of the livestock system identified in the SES framework (see for example, Table 1) which include the actors' attributes, governance system, resource units, and the resource system attributes.

The livestock system's vulnerability stems from various factors including information asymmetry, few actors (buyers) and lack of coordination among the actors (cf. Barrett et $a l ., 2017)$. Digital innovations suggested for the study area such as low-cost community networks have the potential to enable the livestock system actors, and other social actors, to improve information flows and coordination among themselves (cf. Foster et al., 2018). While this is the hoped-for outcome, Toyama (2015) shows that technology only amplifies the intention of the user. Thus, digital infrastructure transformation will only facilitate data flows if the livestock actors intend to improve (or introduce) data flows among themselves. In addition to this, Leonardi (2012) suggests that technology affordances only bring change when these affordances are appropriated by the wider group. Therefore, the digital infrastructure transformation can only yield desired outcomes when the system actors appropriate the affordances of the digital technologies collectively.

However, even though system actors are central to the technology affordances theory, Gaver (1991) also argues that technology affordances are independent of perception or appropriation. Thus, digital infrastructure transformation creates affordances embedded in these technologies and whether actors appropriate the technology affordances or not is a secondary issue. Thus, the establishment of community information centre creates or improves ICT accessibility while the low-cost community network setup enables affordable communication. Whether a community wants to access ICT or not, and whether the community chooses to communicate or not is a secondary aspect.

\section{Empirical approach to impact assessment}

The theoretical impacts presented in the preceding section can be applied across different contexts. However, studies relying on theoretical perspectives only are often criticized as theoretical conjectures of impacts of specific interventions that have often contributed to the imposition of solutions with limited community consultation and/or consideration of local context. Therefore, this study attempts to blend both theoretical and empirical evidence in an effort to achieve a comprehensive impact assessment approach. ${ }^{6}$ The empirical evidence presented in this study was generated during the implementation of the MOSMAC project in Beitbridge between 2015 and 2018.

At the onset of the project, introductory stakeholder meetings (e.g. with community members, local governing authorities, and various government departments) were held in the area. Upon outlining the proposed intervention (project) during these meetings, there were mixed reactions of optimism and pessimism. Pessimistic stakeholders raised several concerns including the following:

\footnotetext{
${ }^{6}$ The theoretical impact assessment may be generalizable while empirical impact assessment may differ from context to context.
} 
For the past decades, we have had several of these projects. They simply come, do research and go. In the end, there is nothing which is left in the community to show for these projects. How different are you from these others?

Indeed, these claims were substantial in that the study area is replete with donor projects working with different funding models. Some organisations only conduct feasibility work and leave, while most research-based projects only engage the communities without significant physical developments in the community. From the stakeholder meetings, there were sentiments that in the community, a project's (intervention) impact could be measured based on what physical artefacts (e.g. computer laboratory, a borehole) it leaves behind beyond the project timeframe. This could be linked to SES and CF in that projects which focus on delivering human constructed facilities, including access to ICTs, are likely to be considered more successful than those which focus on developing the agency of the system actors. Undoubtedly, there are several concerns with adopting this approach. For instance, there is no consideration of whether the society considers the usefulness of what would be left. However, the study findings show that in most cases, the community finds ways to use artefacts (repurposing) but for some artefacts, they have created further divisions in the community as individuals seek control and ownership (further weakening social capital and resilience). ${ }^{7}$

In several discussions with the extension workers during the various phases of the project, it became evident that one way which digital infrastructure transformation would impact the livestock system in the study area, and indeed several other value chains, would be incentivizing the stay of skilled personnel such as livestock technicians, teachers and nurses in the community (improving a community's agency). For instance, before the establishment of the MOSMAC community information centre, the livestock technicians had to travel to the district office to access internet and other services. From the onset of the project, one technician highlighted that:

With internet accessible in my ward, there won't be need for me to go to the district office. I can work from the ward and email the reports, and this will save me time and costs. I also think with more developments like these, the area becomes more inhabitable and there won't be any reason for me to seek a transfer to other districts.

During the engagements with the smallholder farmers, it emerged that the livestock system, specifically auctioning process, was beset with challenges. To develop further insights into these challenges, ranking exercises of these challenges were conducted during participatory mapping activities and the participants identified addressing information asymmetry, reducing transaction costs and improving the capabilities of the farmers to access alternative markets as top priorities. Upon soliciting potential solutions, participants suggested that successful integration of technologies could significantly contribute to solving these challenges. For instance, one participant suggested that:

Bringing ICTs to the communities can be a way to solve several challenges facing the farmers such as poor market information access, lack of knowledge or even poor communication and coordination among the livestock actors. From what you have presented as your project, I think you will help us a lot especially by reducing

\footnotetext{
${ }^{7}$ Miroro (2014) argues that it is critical to also conduct impact assessment in the long run to establish
} residual impact which is often overlooked when end of project evaluations are conducted. 
unnecessary travelling (time \& costs). It will be a crucial advancement if we are able to sell our livestock from our homes, without having to go to the auction when we have other things to attend to at home.

However, from the same engagements with the community and livestock system actors, it was evident that the digital infrastructure transformation would impact certain sections of the livestock system but not others. For example, during the livestock auction attended, buyers did not have cash due to the cash crisis in Zimbabwe. However, buyers were willing to pay using the mobile cash option, Ecocash, and yet most smallholder farmers did not have access to Ecocash (limited use of technology) and generally disliked the option. One farmer even suggested that:

For many years, I have been selling livestock and I have always been paid cash. I am not comfortable to receive livestock payments through the Ecocash platform as this service will charge me extra to access my cash and the agents, at times, do not have cash or the service may go down due to network

Therefore, despite the affordances of mobile technologies (mobile payments), the lack of collective appropriation of technology affordances resulted in the smallholder farmers' rejection of mobile payment option (Ecocash) when buyers at the livestock auction were willing to transact using mobile payment. In the same vein of technology resistance by the community, the empirical evidence also suggested that digital infrastructure transformation may have negative effects on the society such as advancing societal inequalities. For instance, while the technician's willingness to commit to staying in the study area was encouraging, it was equally worrying that the sentiments of other technicians and government officials suggested potential power dynamics. For instance, one technician indicated that:

"Once the facilities are complete, we will be working from here all the time"

On the other hand, an elderly farmer remarked that:

"We will leave this technology to the young ones and the educated ones"

Such remarks raised by the elderly people indeed reflected what occurred in Beitbridge. Following the establishment of the MOSMAC information centre, fewer elderly people indicated interest in using the facility. Thus, despite the MOSMAC intervention targeting livestock farmers, the setup of the community information centre at a local school suggested that the school was meant to benefit in some ways. Since the Zimbabwean government has mandated the teaching of ICTs in schools, the teachers at the school seized the opportunity to use the MOSMAC facility to teach ICTs. The school head remarked that:

"The facility will assist us in teaching computer lessons to the children. As you can see, we were using one laptop for more than 30 children and we did not have access to internet. We are going to benefit more than anyone else in the community"

These sentiments were also echoed by the senior teacher at a primary school where the MOSMAC community information centre is located. This finding reflects that 
improvements of digital infrastructure plays a key role in attracting and retaining key personnel in a rural area. The above remarks indicate that the intervention has positive unintended consequences on the community due to its repurposing. In this regard, it is critical therefore to extend the impact assessment to also explore these unintended consequences, whether positive or negative.

\section{Discussion}

In the next decade, investments in digital infrastructure in marginalised communities are likely to increase. These investments will be driven by many factors among them, the need to profit as well as the genuine need to solve societal problems, or alternatively, the need to develop marginalised communities. Oliver et al. (2018:1) indicate, “... our knowledge regarding [complex systems] is fragmented hindering the development of coordinated solutions" and in all this confusion "a significant challenge is to prioritize suites of interventions that can effectively transform the [complex] system." Overcoming this challenge will rely on making accurate decisions on what interventions to deploy, and in what areas; both of which hinge upon robust and comprehensive impact assessment. However, current impact assessment approaches are fraught with many challenges. Thus, this study has proposed blending multiple impact assessment approaches.

Firstly, this study has demonstrated that impact assessment can be done at different stages of the project lifecycle. The study showed that even at inception meetings with local authorities, there were already suggestions of impact indicators. Similarly, at every stage of implementing the MOSMAC intervention, there were various impact related elements which could be established (e.g. remarks, gestures, and non-verbal actions). This is in line with Mthoko and Khene (2018) who argue that measuring a project's impact based on baseline data "limits the potential learning that could be occurring throughout a project's lifecycle." In addition to this, the study acknowledges that theories and framework are designed with the end point being identifying outcomes (e.g. for the CF framework, outcomes relate to choice; while in SES framework, outcomes are left to be imagined). However, this study has suggested that impacts of interventions such as the MOSMAC project can be explored throughout a project's lifecycle using the 'building blocks' of these frameworks and theories. The study has demonstrated how impact assessment can be identified in relation to the transformation of the attributes of a SES, transformation of agency and structure of a system (or community). This helps to identify the often, hidden and complex impacts, which otherwise would be omitted from traditional impact assessment.

In empirical terms, the study has demonstrated that the MOSMAC intervention can have different impacts to different groups. In this study, teachers and extension workers were found to have interest in the intervention compared to the livestock farmers. Furthermore, school children were set to benefit more through access to computers and Internet. Therefore, even though the initial project plan had established specific targets, the intervention deviated, achieving unintended impacts in the process. In addition to this, the study suggests that philosophical approaches can further play a key role towards assessing impacts of interventions. For instance, using the assemblages perspective suggests that the impact of an intervention extends to how the intervention 'relates' to other existing infrastructure. In this context, digital infrastructure transformation in the community, specifically the establishment of the community information centre, 
represents a creation of a metaphorical agora (cf. Matavire, 2016) which in the ancient times was central to social and political fabric of communities (ibid; Thomson \& Wycherley, 1972). In the study area, due to spatial dynamics, e.g. vast spaces between households, interactions are limited to social functions and this has impacted the social capital among the smallholder farmers. Outside of the social functions, there are limited, if any, spaces accommodative to all age groups. As Matavire (2016) illustrates, infrastructure changes create new spaces for interaction, both physical and virtual interaction. However, for now, the physical interaction, meeting at the community centre, will be realised sooner than the virtual (cf. Gwaka, 2018).

\section{Conclusion}

Concurring with prior studies (Mavedzenge et al., 2008; Barret et al., 2017; Rey Moreno et al., 2016) on the need to continue transforming digital infrastructure in rural communities, this study presented an ICT intervention in rural Zimbabwe. Furthermore, the study has acknowledged challenges prevailing in impact assessment, and thus presented a blending of approaches towards impact assessment on the MOSMAC intervention. The findings presented in this study suggest that different impact assessment approaches (e.g. theoretical vis-à-vis empirical) often yield different results. Therefore, the blending of the different approaches is a first step towards achieving comprehensive context-sensitive impact assessment. Furthermore, with each approach, extended analysis of the system under investigation blended collaborative formulation of impact assessment metrics, driven by internal and external actors. Context-appropriate metrics when conducting such blended impact assessment. We therefore conclude that the blending of multiple approaches to undertake impact assessment can be key towards achieving a comprehensive impact assessment to yield results for policy making. However, this process is not without challenges. The process can be time-consuming and may require more resources (expertise) as well as careful analysis and selection of approaches to blend. Future studies extensively exploring different systems (value chains) are also encouraged to improve the diversity of impact metrics, including building knowledge on system-specific metrics. In terms of policy, this study hopes policy makers realise the need to improve digital infrastructure in rural communities and in practice, the study hopes it provides impact evaluators with a challenging perspective to undertake their work. 


\section{References}

Anadon, L. D., Chan, G., Harley, A., Matus, K., Moon, S., Murthy, S. L., \& Clark, W. C. (2015). Making technological innovation work for sustainable development. Harvard Kennedy School.

Attwood, H., Diga, K., Braathen, E., \& May, J. (2013). Telecentre functionality in South Africa: Re-enabling the community ICT access environment.

Avgerou, C. (2010). Discourses on ICT and development. Information Technologies \& International Development, 6(3), $\mathrm{pp}-1$.

Barrett, C. B., Christian, P., \& Shiferaw, B. A. (2017). The structural transformation of African agriculture and rural spaces: introduction to a special section. Agricultural Economics, 48(S1), 5-10.

Batuo, M. E. (2015). The role of telecommunications infrastructure in the regional economic growth of Africa. The Journal of Developing Areas, 49(1), 313-330.

CFS: Committee on World Food Security. (2016). Sustainable Agricultural Development for Food Security and Nutrition: What Roles for Livestock? Retrieved May 8, 2018 from http://www.fao.org/3/a-ms023e.pdf

Cooke, J. G. (2015). The state of African resilience: Understanding dimensions of vulnerability and adaptation. Rowman \& Littlefield.

Donner, J., \& Toyama, K. (2009). Persistent themes in ICT4D Research: priorities for intermethodological exchange. 57th Session of the International Statistics Institute, Durban, South Africa, 17-21.

Ely, A., Van Zwanenberg, P., \& Stirling, A. (2014). Broadening out and opening up technology assessment: Approaches to enhance international development, co-ordination and democratisation. Research Policy, 43(3), 505-518.

Enenkel, M., See, L., Bonifacio, R., Boken, V., Chaney, N., Vinck, P., ... \& Anderson, M. (2015). Drought and food security-Improving decision-support via new technologies and innovative collaboration. Global Food Security, 4, 51-55.

Foster, C., Graham, M., Mann, L., Waema, T., \& Friederici, N. (2018). Digital control in value chains: Challenges of connectivity for East African firms. Economic Geography, 94(1), 68-86.

Friederici, N., Ojanperä, S., \& Graham, M. (2017). The impact of connectivity in Africa: Grand visions and the mirage of inclusive digital development. The Electronic Journal of Information Systems in Developing Countries, 79(1), 1-20.

Ganju, K. K., Pavlou, P. A., \& Banker, R. D. (2015). Does information and communication technology lead to the well-being of nations? A Country-Level Empirical Investigation.

Gaver, W. W. (1991, April). Technology affordances. In Proceedings of the SIGCHI conference on Human factors in computing systems (pp. 79-84). ACM.

Gomez, R., \& Pather, S. (2012). ICT evaluation: Are we asking the right questions?. The Electronic Journal of Information Systems in Developing Countries, 50(1), 1-14.

Guston, D. H., \& Sarewitz, D. (2002). Real-time technology assessment. Technology in society, 24(1-2), 93-109. 
Gwaka, L. T. (2017). Digital Technologies and Sustainable Livestock Systems in Rural Communities. The Electronic Journal of Information Systems in Developing Countries, 81(1), 1-24.

Gwaka, L. T., May, J., \& Tucker, W. (2018). Towards low-cost community networks in rural communities: The impact of context using the case study of Beitbridge, Zimbabwe. The Electronic Journal of Information Systems in Developing Countries, e12029.

Gwaka, L. T. (2018). Digital technologies and youth mobility in rural Zimbabwe. The Electronic Journal of Information Systems in Developing Countries, e12025.

Harris, J., Mishra, P., \& Koehler, M. (2009). Teachers' technological pedagogical content knowledge and learning activity types: Curriculum-based technology integration reframed. Journal of Research on Technology in Education, 41(4), 393-416.

Harris, R. W. (2016). How ICT4D research fails the poor. Information Technology for Development, 22(1), 177-192.

Heeks, R. (2014). Future priorities for development informatics research from the post-2015 development agenda. IDPM Development Informatics Working Papers.

IFAD. (2016). Rural Development Report 2016: Fostering Inclusive Development, International Fund for Agricultural Development, Rome, accessed from https://www.ifad.org/documents/10180/4bcb3209-0773-489a-b93a-57fae6581b69, 08 June, 2018.

Jensen, R. (2007). The digital provide: Information (technology), market performance, and welfare in the South Indian fisheries sector. The quarterly journal of economics, 122(3), 879-924.

Kleine, D. (2010). ICT4WHAT? - Using the choice framework to operationalise the capability approach to development. Journal of International Development, 22(5), 674-692.

Kleine, D. (2013). Technologies of choice?: ICTs, development, and the capabilities approach. MIT Press.

Kuriyan, R., Nafus, D., \& Mainwaring, S. (2012). Consumption, technology, and development: the "poor" as "consumer". Information Technologies \& International Development, 8(1), pp-1.

Leonardi, P. M. (2012). When does technology use enable network change in organizations? A comparative study of feature use and shared affordances. MIS Quarterly, 37(3), 749-775

Lévi-Strauss, C. Anticipating Blockchain for Development: Data, Power and the Future.

MacKenzie, D., \& Wajcman, J. (1999). The social shaping of technology (No. 2nd). Open university press.

Madon, S. (2000). The Internet and socio-economic development: exploring the interaction. Information technology \& people, 13(2), 85-101.

Majchrzak, A., Markus, M. L., \& Wareham, J. (2016). Designing for digital transformation: Lessons for information systems research from the study of ICT and societal challenges. MIS Quarterly, 40(2), 267-277.

Marshall, G. (2015). A social-ecological systems framework for food systems research: accommodating transformation systems and their products. International Journal of the Commons, 9(2). 
Matavire, R. (2016). Health information systems development: producing a new agora in Zimbabwe. Information Technologies \& International Development, 12(1), 35-51.

Mavedzenge, B. Z., Mahenehene, J., Murimbarimba, F., Scoones, I., \& Wolmer, W. (2008). The dynamics of real markets: cattle in southern Zimbabwe following land reform. Development and Change, 39(4), 613-639.

May, J., Dutton, V., \& Munyakazi, L. (2014). Information and communication technologies as a pathway from poverty: evidence from East Africa. ICT pathways to poverty reduction: Empirical evidence from East and Southern Africa, 33-52.

McGinnis, M., \& Ostrom, E. (2014). Social-ecological system framework: initial changes and continuing challenges. Ecology and Society, 19(2).

Miroro, O. O. (2014). A Realistic Explanation of Long Run Development Interventions Contexts, Adaptations and Outcomes of Dairy Improvement in Kenya (Doctoral dissertation, University of KwaZulu-Natal, Durban).

Mthoko, H., \& Khene, C. (2018, August). Rethinking ICT4D Impact Assessments: Reflections from the Siyakhula Living Lab in South Africa. In International Development Informatics Association Conference (pp. 48-60). Springer, Cham.

Oliver, T. H., Boyd, E., Balcombe, K., Benton, T. G., Bullock, J. M., Donovan, D., ... \& Nunes, R. J. (2018). Overcoming undesirable resilience in the global food system. Global Sustainability, 1 .

Oosterlaken, I. (2009). Design for development: A capability approach. Design issues, 25(4), 91102.

Ospina, A. V., \& Heeks, R. (2010). Linking ICTs and climate change adaptation: A conceptual framework for e-Resilience and e-Adaptation.

Ostrom, E. (2009). A general framework for analyzing sustainability of social-ecological systems. Science, 325(5939), 419-422.

Palvia, P., Baqir, N., \& Nemati, H. (2018). ICT for socio-economic development: A citizens' perspective. Information \& Management, 55(2), 160-176.

Pather, S., \& Uys, C. (2010, January). A strategy for evaluating socio-economic outcomes of an ICT4D programme. In System Sciences (HICSS), 2010 43rd Hawaii International Conference on (pp. 1-11). IEEE.

Pather, S. (2017, September). Contextualising Information Systems Evaluation Research: Towards a Classification of Approaches. In ECISM 2017 11th European Conference on Information Systems Management (p. 252). Academic Conferences and publishing limited.

Pawson, R. (2006). Evidence-based policy: a realist perspective. Sage.

Picciotto, R. (2014). Have Development Evaluators Been Fighting the Last War... And If So, What is to be Done?. IDS Bulletin, 45(6), 6-16.

Prinsloo, T., \& De Villiers, C. (2017). A Framework to Define the Impact of Sustainable ICT for Agriculture Projects: The Namibian Livestock Traceability System. The Electronic Journal of Information Systems in Developing Countries, 82(1), 1-22.

Qureshi, S. (2015). Are we making a better world with information and communication technology for development (ICT4D) research? Findings from the field and theory building. 
Rey-Moreno, C., Blignaut, R., Tucker, W. D., \& May, J. (2016). An in-depth study of the ICT ecosystem in a South African rural community: unveiling expenditure and communication patterns. Information Technology for Development, 22(sup1), 101-120.

Sabbagh, K., Friedrich, R., El-Darwiche, B., Singh, M., Ganediwalla, S. A. N. D. E. E. P., \& Katz, R. A. U. L. (2012). Maximizing the impact of digitization. The global information technology report, 121-133.

Schot, J., \& Rip, A. (1997). The past and future of constructive technology assessment. Technological forecasting and social change, 54(2-3), 251-268.

Sherwood, G., Cherian, U. K., Horton-Deutsch, S., Kitzmiller, R., \& Smith-Miller, C. (2019). Reflective practices: meaningful recognition for healthy work environments. Nursing Management, 26(1).

Sørensen, C. (2013). Digital platform and-infrastructure innovation. Mobile Strategy Challenges (In Japanese). H. Higashikuni (ed). Nikkan Kogyo Shimbun Ltd. Tokyo.

Srinivasan, J., \& Burrell, J. (2015). On the importance of price information to fishers and to economists: Revisiting mobile phone use among fishers in Kerala. Information Technologies \& International Development, 11(1), pp-57.

Takavarasha, S., \& Makumbe, J. (2012). The effect of politics on ICT4D: A case of Econet Wireless's struggle for a license in Zimbabwe. International Journal of E-Politics (IJEP), 3(3), 40-60.

Thompson, H. A., \& Wycherley, R. E. (1972). The Agora of Athens: the history, shape and uses of an ancient city center. The Athenian Agora, 14, iii-257.

Toyama, K. (2015). Geek heresy: Rescuing social change from the cult of technology. PublicAffairs.

Toyama, K. (2017). From needs to aspirations in information technology for development. Information Technology for Development, 1-22.

Van Stam, G., \& Mweetwa, F. (2012). Community Radio Provides Elderly a Platform to Have Their Voices Heard in rural Macha, Zambia. The Journal of Community Informatics, $8(1)$.

Vogt, F., Tayler-Smith, K., Bernasconi, A., Makondo, E., Taziwa, F., Moyo, B., ... \& Reid, A. (2015). Access to CD4 testing for rural HIV patients: findings from a cohort study in Zimbabwe. PloS one, 10(6), e0129166.

Walsham, G. (2017). ICT4D research: reflections on history and future agenda. Information Technology for Development, 23(1), 18-41.

Westerveld, R. (2012). 10. Inverse Telecommunications: The Future for Rural Areas in Developing Countries?. Inverse infrastructures: Disrupting networks from below, 187.

Young, S. L. (2017). Unintended consequences of 21st century technology for agricultural pest management. EMBO reports, 18(9), 1478-1478.

ZimStat. (2016). The Food Poverty Atlas: small area poverty estimation. Retrieved May 10, 2018 from http://www.zimstat.co.zw/sites/default/files/img/Zimbabwe\%2520Food\%2520Poverty \%2520Atlas2016_FINAL_A4\%5B1\%5D.pdf 